\title{
Calculated Potential Bedload Versus Real Transported Sands along the Guadiana River Estuary (Spain-Portugal)
}

\author{
Juan A. Morales ${ }^{1, *}$, Claudio Lozano ${ }^{1}$ and Mouncef Sedrati ${ }^{2}$ \\ 1 Department of Earth Sciences, Universidad de Huelva, Avenue 3 de Marzo, s/n. E-21007 Huelva, Spain; \\ almiranta@hotmail.com \\ 2 Université Bretagne Sud, Laboratoire Géosciences Ocean UMR CNRS 6538., BP 573, 56017 Vannes CEDEX, \\ France; mouncef.sedrati@univ-ubs.fr \\ * Correspondence: jmorales@uhu.es
}

Received: 10 October 2019; Accepted: 29 October 2019; Published: 5 November 2019

\begin{abstract}
The Guadiana estuary is a coastal system located in the southwest of the Iberian Peninsula and is the natural border between Portugal and Spain. It is a rock-bounded estuary which extends along more than $40 \mathrm{~km}$ and is characterized by a semidiurnal mesotidal regime. This paper represents an approach to the bedload transport across two flow sections located in the fluvial and marine domains. In the fluvial profile, the most frequent bedform is the plane bed. In the marine area the bed of the deep channel is composed of well-sorted sand, while a lateral bar displays partially cohesive sediments with dominant fine sands in a matrix of clayey silts. Data were acquired during spring and neap tides. Near-bottom water velocities were registered by an acoustic Doppler current profiler (ADCP). Density and bed rugosity were determined in sediment samples. These data were employed using Bagnold's equation (1963) to quantify the potential bedload $(Q b)$. Further, real bedload values $(\mathrm{Sb})$ were obtained by using Poliakoff traps. The comparison of the results of $Q b$ under both ebb and flood conditions demonstrated a clear river-to-sea net transport in both sectors. The values of $S b$ were lower than those of $Q b$ in every condition. The sand input across the fluvial estuary cannot supply the potential bedload in the lower domain of the channel, thereby causing a deficit that explains this lack of agreement between potential and real transport.
\end{abstract}

Keywords: Guadiana Estuary; tidal currents; potential bedload transport; real sediment input

\section{Introduction}

The calculation of the potential bedload transported by fluvial and tidal currents has been a focus of attention over the last few years because understanding the arrival of sand from the continent to the coast has become an important aspect of the correct management of coastal systems [1-10]. The sedimentary material transported along the water-bed interface can be understood as a bedload. Normally, this material is transported by rolling, dragging, or saltation, with regard to the individual movement of the particles, although this movement can also be regarded in a collective way with reference to the migration of bedforms. Bedform dynamics have been described by numerous authors [1-6]. A good synthesis of those which have been studied was presented recently by Wu et al. in 2009 [8]. In general terms, all authors accept that equilibrium bedforms reflect how the patterns of the net movement of the sedimentary bedload in each channel transect [9]. Most works elaborated during the last decades of the twentieth century agree that bedforms (dimensions and orientation) are a good parameter with which to qualitatively estimate bedload [10-12] and are especially useful in multidirectional systems such as estuarine channels $[8,13]$. 
The quantification of the bedload is an even more complex problem. Both direct and indirect methods are used to analyze this quantification. Direct methods using sediment traps are not very common because, as many authors highlight, there is a real difficulty in avoiding making very large methodological errors derived from an incorrect installation [14]. Thus, the most commonly used methods are indirect ones that use equations to calculate the potential transport [15-18]. The criteria used to establish these equations are different but all the equations coincide in their use of the grain size of the transported material in relation to the energy of the fluid flow. In recent years, some of these equations have been used for calculations in spatial grids by means of mathematical models of transportation [19-21]. These models can couple together different modules, thereby generating 2D and 3D patterns of flow circulation and sediment transport [22].

The strong regulation of the Iberian rivers during the last 40 years has modified the hydrodynamic behavior for most parts of the fluvio-marine systems located in their mouths, creating interest for the research teams involved in coastal management. Examples of these studies include those on the Ebro River mouth [23-25] or the Guadiana Estuary [26-30]. Nevertheless, some of these papers emphasize the calculation of the potential transport, but do not take into account that real transport is not only a function of the capability of the currents to transport sands but also depends on the availability of the sediments to be transported. It is necessary to consider that the differences between the predicted and measured transport rates in tidal systems have been widely discussed by different authors [31,32]. Given that, this study is part of the continuity of research work dedicated to the characterisation of potential and reel sediment transport in tidal complex systems. In fact, this paper may compare the calculated potential transport with the measured real sand transport obtained by means of installing the bedload sediment traps in this mesotidal rock bounded estuary. This combined approach (in situ measurements versus empirical estimation) for the determination of bedload sediment transport would allow the improvement of bedload sediment transport estimations and the calibration in the future of sediment transport formulas for a better characterization of hydro-morpho-sedimentary processes in complex estuarine environments.

\section{Site Description}

The Guadiana estuary is defined as a rock-bounded estuary [27] composed of a 60-km-long tight estuarine channel. This channel consists of successive meanders imposed by two families of faults that displace blocks of Palaeozoic hard lithologies [28,33]. Nevertheless, in the marine area, the estuary widens when crossing Cenozoic formations [34]. There, the system develops a prograding wave-dominated delta consisting of sandy barriers separated by salt marsh bodies [28]. The entire estuary is characterized by a mesotidal regime. The mean tidal range is $2.1 \mathrm{~m}$ but reaches $3 \mathrm{~m}$ during spring tides and can be less than $1 \mathrm{~m}$ during neap tides. Because of this narrow morphology, the tide behaves synchronically along the outer $40 \mathrm{~km}$ of the estuary [35]. The marine area is affected by the dominant SW waves, with a mean significant height of $0.5 \mathrm{~m}$. The orientation of the main channel inhibits the action of these waves in the estuarine channel. Only under north wind conditions can small sea waves be generated in the estuarine channel, but these are surficial waves that do not incite the movement of the water mass.

Since the 1960s, the fluvial basin has been regulated with more than 40 dams. The last of them is named Alqueva, which is the biggest dam in Europe with a capacity of $41.5 \times 10^{8} \mathrm{~m}^{3}$ and an inundated surface of $250 \mathrm{~km}^{2}$, which is situated $154 \mathrm{~km}$ up to the estuary mouth and $90 \mathrm{~km}$ upstream to the last point of tidal influence. This dam completely inhibits the arrival of sands to the estuary from the main river channel, which presently includes only the lateral minor effluents, and the rework of the ancient bars located down the dam are responsible for the entering of the sand into the lower part of the river [30].

The fluvial and marine sectors of the estuarine channel have a meandering morphology. Each meander represents a section consisting of a pool and a lateral tidal bar. Between successive meanders, the inflection points represent a symmetric section where the pools and bars are absent [28]. 
This paper compares potential and real sand transport across two cross sections of the estuarine channel, one in the fluvial estuary and the other in the marine sector. The first one is located at $39 \mathrm{~km}$ from the estuarine mouth in a zone dominated by fresh water; the second section is located at $6.5 \mathrm{~km}$ from the most external point of the estuarine channel (Figure 1). Both profiles have the typical section of a left meander with an asymmetric morphology displaying the pool in the eastern margin and a shallow lateral bar on the western bank. The maximum depth observed in both profiles is similar. Nevertheless, the inner profile is narrower and the lateral bar is less marked (Figure 2). The preliminary results of this experiment, describing only the marine area, were previously presented in the first meeting of the Mediterranean Littorals. Afterwards, the results were derived into a paper [36].

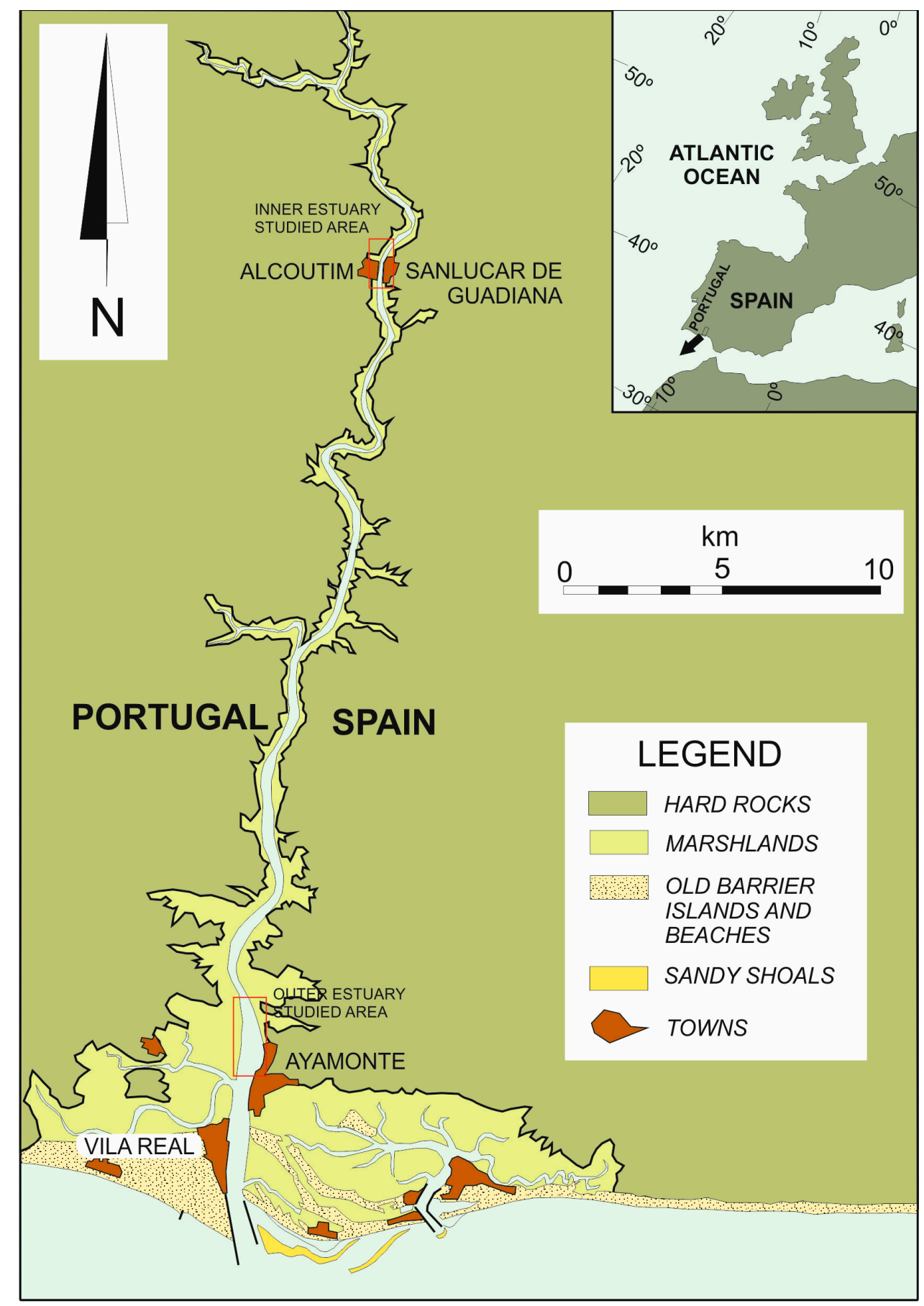

Figure 1. Location of the studied sections on the inner and outer sectors of the Guadiana Estuary. 
A) FLUVIAL SECTION: SANLUCAR

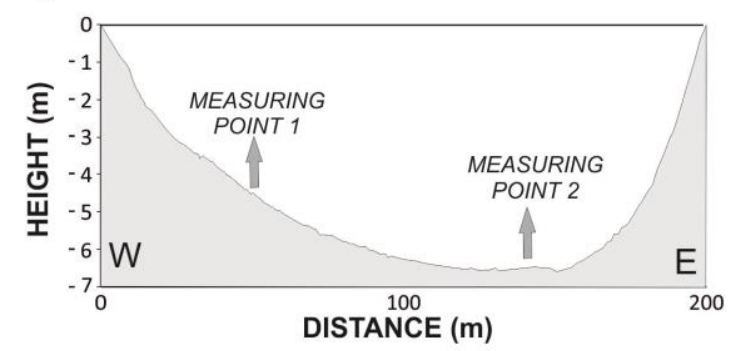

B) MARINE SECTION: AYAMONTE

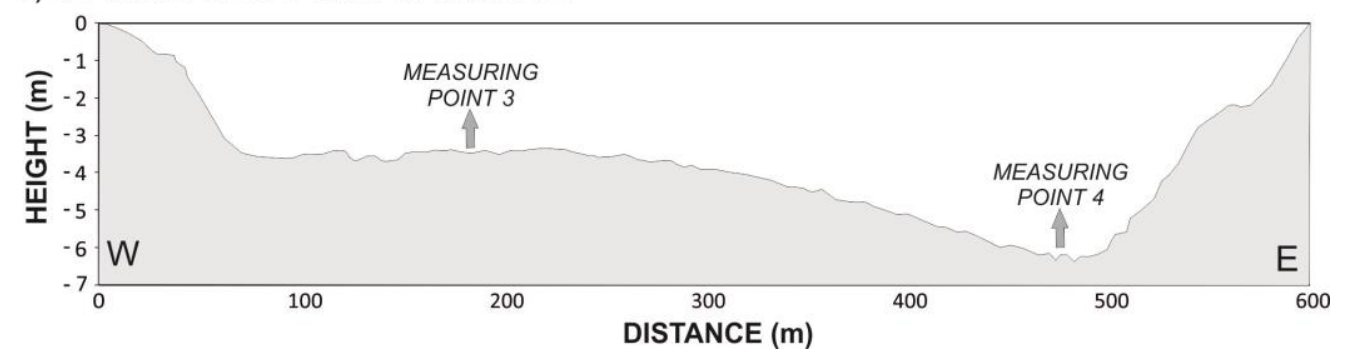

Figure 2. Flow sections where the measure points (acoustic Doppler current profiler (ADCP) and sediment traps) are indicated. (A) Inner (fluvial) section and (B) Outer (marine) section.

\section{Methods}

The data for this paper were obtained during two surveys developed to study the behavior of the sand material transported across the channel of this estuarine system. The first survey was planned to determine the bed's physiography by means of a Side Scan Sonar mosaic and was carried out in July 2008. For this study, a Side Scan Sonar CM2000 (CMAX Ltd., Dorset, UK) was used with a frequency of $325 \mathrm{kHz}$. The resolution for acquisition was $50 \mathrm{~m}$ per band. A geotiff mosaic of images was elaborated using ARCVIEW 3.2.

A second survey was specially developed to quantify the potential and real bedload transport. The data acquisition was carried out between the end of June and the first fortnight of July 2010. During 29 and 30 June 2010, a bathymetry was deployed using an echo sound Valeport Midas Surveyor with a frequency of $210 \mathrm{kHz}$. From 1 to 5 July, 20 sediment samples were caught by means of a Van Veen drag (seven in the fluvial studied area and 13 in the marine one). The grain size distributions of the sediment samples were analyzed by the General Research Services of the University of Huelva using a Laser Difractometer Malvern Mastersizer 2000 (Malvern Panalytical, Almelo, The Netherlands) able to determine the percentages of grain fractions between 2 and $0.0002 \mathrm{~mm}$.

Both the bathymetry acquisition points and the sediment samples were geo-referenced by means of a dGPS EGNOS with 12 channels to obtain XYZ files with accurate positions. The absolute value of $Z$ was obtained by correcting with a tidal curve from the harbor of Ayamonte (marine area) and a propagation curve from Ayamonte to Sanlucar (fluvial area). The XYZ data were processed by a Delaunay triangulation in the module 3D Terrain model of the software Hypack 2009 (Middletown, CT, USA).

The tidal currents were also studied by installing an acoustic Doppler current profiler (ADCP) (Teledyne RD Instruments, Workhorse model, Poway, CA, USA), which worked during two different tidal cycles (neap and spring) in July 2010. In the fluvial domain, the neap tide velocity profile was measured on 6 July (coefficient 0.46 and tidal range $1.50 \mathrm{~m}$ ), whereas the spring tide current profile was obtained on 14 July (coefficient 0.90 and tidal range $2.85 \mathrm{~m}$ ). In the marine transection, the neap tidal currents were measured on 5 July (coefficient 0.44 and tidal range $1.48 \mathrm{~m}$ ) and the currents of the spring tides were obtained on 15 July (coefficient 0.91 and tidal range $2.95 \mathrm{~m}$ ). The measurements in the fluvial and marine domains could not be registered the same day due to a limit in the number 
of current meters. To solve this, we found tides with similar characteristics (coefficients and tidal ranges). The $\mathrm{ADCP}$ system was installed in a floating platform measured from the surface to the bed. The velocity was measured just as $0.5 \mathrm{~m}$ from the bed, that was used as the near-bottom velocity.

The values of potential bedload transport $(Q b)$ were obtained from the equation of Bagnold (1963) [15], i.e.,

$$
Q b=\left(K_{1} \delta s U^{* 3}\right) /(d g)
$$

where $g$ is the value of the gravity acceleration $\left(9.81 \mathrm{~m} / \mathrm{s}^{2}\right)$ and $d$ is the dimensionless parameter that relates the density of the sediment grains with the density of the water, i.e.,

$$
d=(\delta s-\delta) / \delta
$$

where $\delta s$ is the average density of sediment grains $\left(2.61 \times 10^{6} \mathrm{~g} / \mathrm{m}^{3}\right) ; \delta$ is the density of the water $\left(1.011 \times 10^{6} \mathrm{~g} / \mathrm{m}^{3}\right.$ in the fluvial area and $1.023 \times 10^{6} \mathrm{~g} / \mathrm{m}^{3}$ in the marine area); and $K_{1}$ is the coefficient related to the drag force, the fluid density, and the grain size. For this work, $K_{1}$ was calculated using the experimental equation suggested by Wang and Gao (2001) [37], i.e.,

$$
K_{1}=0.10 \exp \left(0.17 / D_{50}\right)
$$

where $D_{50}$ is the mean grain size diameter of the sediment (the size that represents the $50 \%$ of the sample) and $U^{*}$ is the current velocity at the water-sediment interface and was calculated using the measured near-bottom velocity by the equation

$$
U^{*}=\left(0.4 U_{Z}\right) / \operatorname{Ln}\left(30 Z / 3 D_{10}\right)
$$

where $U_{Z}$ is the near-bottom measured velocity (obtained at a distance $Z$ from the bed); $Z$ is the distance from the current meter to the bed (blanking distance $=0.50 \mathrm{~m}$ ); and $D_{10}$ is the diameter that represents $10 \%$ of the coarser grains of the sediment.

Bagnold's equation was chosen because it is based on criteria for the energy balance between the water flow and the mechanical equilibrium of the particles, taking into account their grain size and density, in relation to the bed's rugosity and the fluid's density. This equation has been demonstrated to be useful for non-cohesive beds formed by particles with a variety of different diameters between sands and small types of gravel, like those observed in our area. A comparison between the equations has been suggested by different authors, and their applicability was described by Guillen et al. in 1994 [24]. Building upon the work of these authors, the equation suggested by Einstein in 1942 [16] was designed for beds formed by unimodal sands, where all particles have the same diameter, geometry, and density. Other equations, such as those suggested by Yalin in 1963 [18], were designed for a constant flow of particles, whereas the equation suggested by Van Rijn in 1981 [17] is designed for flume experiments and introduces some parameters that are difficult to measure in field experiments, such as the height of the particle jumps. In this experiment, Bagnold's formula was the only one that offered results on the same order of magnitude as those observed in direct measurements of real transport.

The equations were employed by introducing the current velocity values in timeslots of $5 \mathrm{~min}$, calculating the mean $U^{*}$ for each interval. The values of $Q b$ obtained for each interval were integrated to obtain the total $Q b$ values (in $\mathrm{g} / \mathrm{cm}$ ) for the complete semicycles of the ebb and flood. The values of $Q b$ were also calculated for the entire flow section (in tons). In the inner study area, the water-sediment interface along the flow section was $200 \mathrm{~m}$ (excluding the meters with the rocky bed), in which $100 \mathrm{~m}$ were calculated using the values for the currents obtained from measuring points 1 and 100 with the currents of measuring point 2. In the outer study area, the flow section was $530 \mathrm{~m}$, within which $350 \mathrm{~m}$ was calculated using the values of the currents obtained from measuring point 3 and 180 with the currents of measuring point 4 .

The calculated values of $Q b$ were compared with direct measurements of real bedload transport (Sb). To obtain these measures, Poliakoff-type sediment traps [38] were installed at the bottom of the 
estuarine channel at the same place and time that the ADCP was used to measure the tidal currents. This sediment trap was used to catch the sand transported as bedload during the complete semicycles of the flood and ebb. The bedload transport $(S b)$ can be determined as

$$
S b=G /(b T)
$$

where $G$ is the dry mass of the caught sediment $(g), b$ is the width of the intake opening $(0.3 \mathrm{~m})$, and $T$ is the time of measuring $(s)$.

The used sediment traps are the same as those successfully used in the Ebro River delta [23-25] and in the Piedras River mouth, which is located only $30 \mathrm{~km}$ to the east of this study area [39]. The traps were removed by divers to ensure the correct orientation following the current and were also recovered by diving to try to avoid the loss of sand during the process of recovery. The first traps were installed during a neap tide ( 5 and 6 July) in the slack moment of the flood-to-ebb transition and extracted in the afternoon at the opposite slack. Therefore, these traps were able to catch the entire ebb semicycle. The second trap set was installed in the same places, right after the first set was recovered, during the ebb-to-flood slack. These traps were removed just after the high tide to catch the sediment of the complete flood semicycle. A new set of traps was installed under the same conditions during a spring tide the (14 and 15 July) in the morning (flood-to-ebb slack) and taken in the afternoon (ebb-to flood slack); these traps were used to catch sediments during the ebb semicycle. Additionally, a final set of traps was installed during the ebb-to-flood slack (to be removed during the flood-to-ebb slack) to function during the flood semicycle.

\section{Geomorphological and Sedimentological Results}

\subsection{Bathymetry}

The distribution of depths is similar in the two studied areas (Figure 3). In both cases, the isobaths allow us to identify a channel $6 \mathrm{~m}$ deep at the Spanish border and a shallow lateral tidal bar located between 2 and $4 \mathrm{~m}$ deep. In the studied area of the fluvial domain (inner estuary), there is a slight transition between the deep channel and the bar (Figure 3), which presents a tilt of $6 \%$ and a narrow wideness. In the studied area of the marine domain (outer estuary), the bar is near horizontal and presents a transition to the intertidal channel margin by means of a two-meter-high slope (Figure 3). The flow section (using the mean water level as a reference) is $960 \mathrm{~m}^{2}$ in the fluvial studied profile and $1465 \mathrm{~m}^{2}$ in the marine profile, with a minor width for the fluvial profile and a less developed bar than that in the marine area.

To the south of both studied flow sections, there is a westward displacement of the deeper channel where it approaches the Portuguese border, while a new lateral tidal bar appears along the eastern Spanish bank.

Taking into account this bathymetric distribution, both the currents and the real bedload transport were measured in two different points of the transversal sections (Figure 2). In each section, a measurement point was located on each lateral bar and another was located in the deeper part of the channel. 
A) INNER ESTUARY AREA

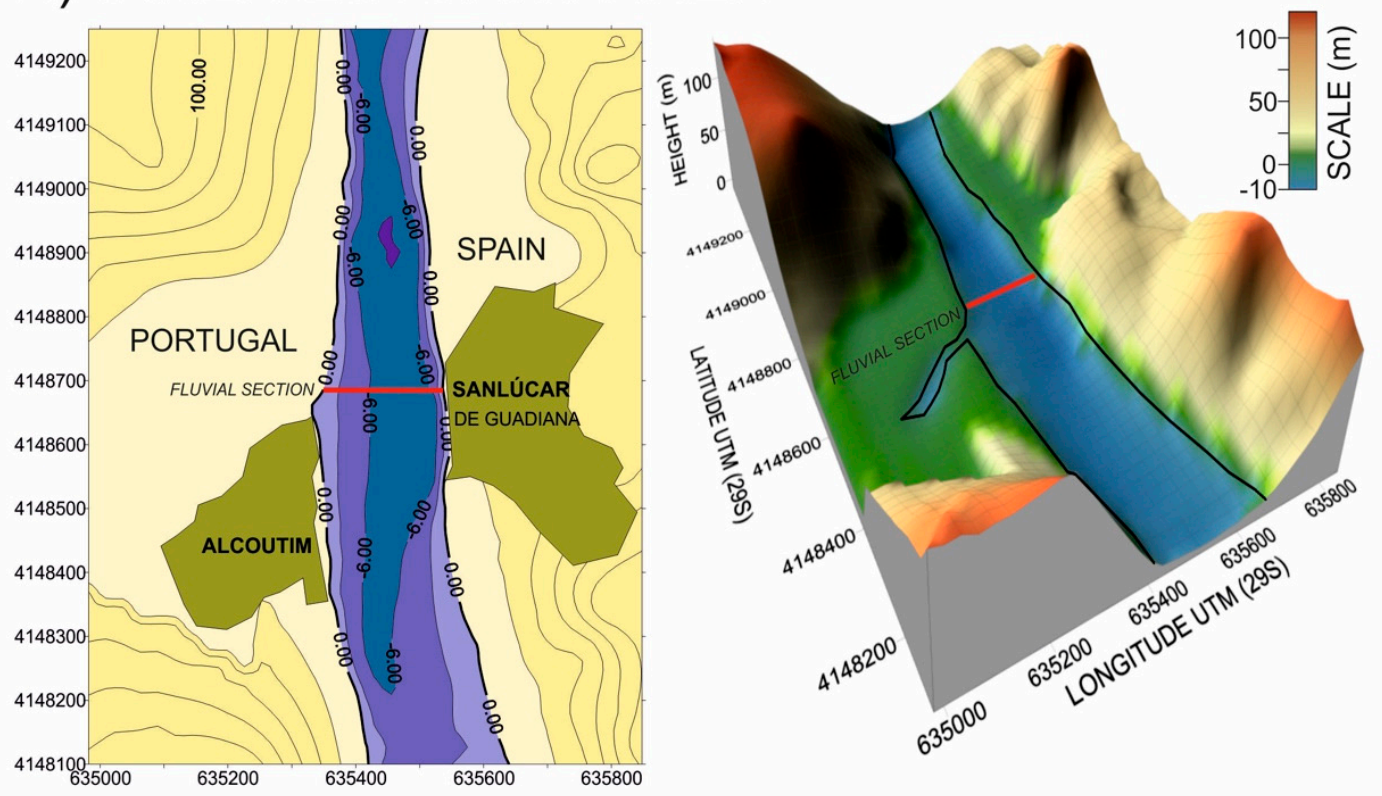

\section{B) OUTER ESTUARY AREA}
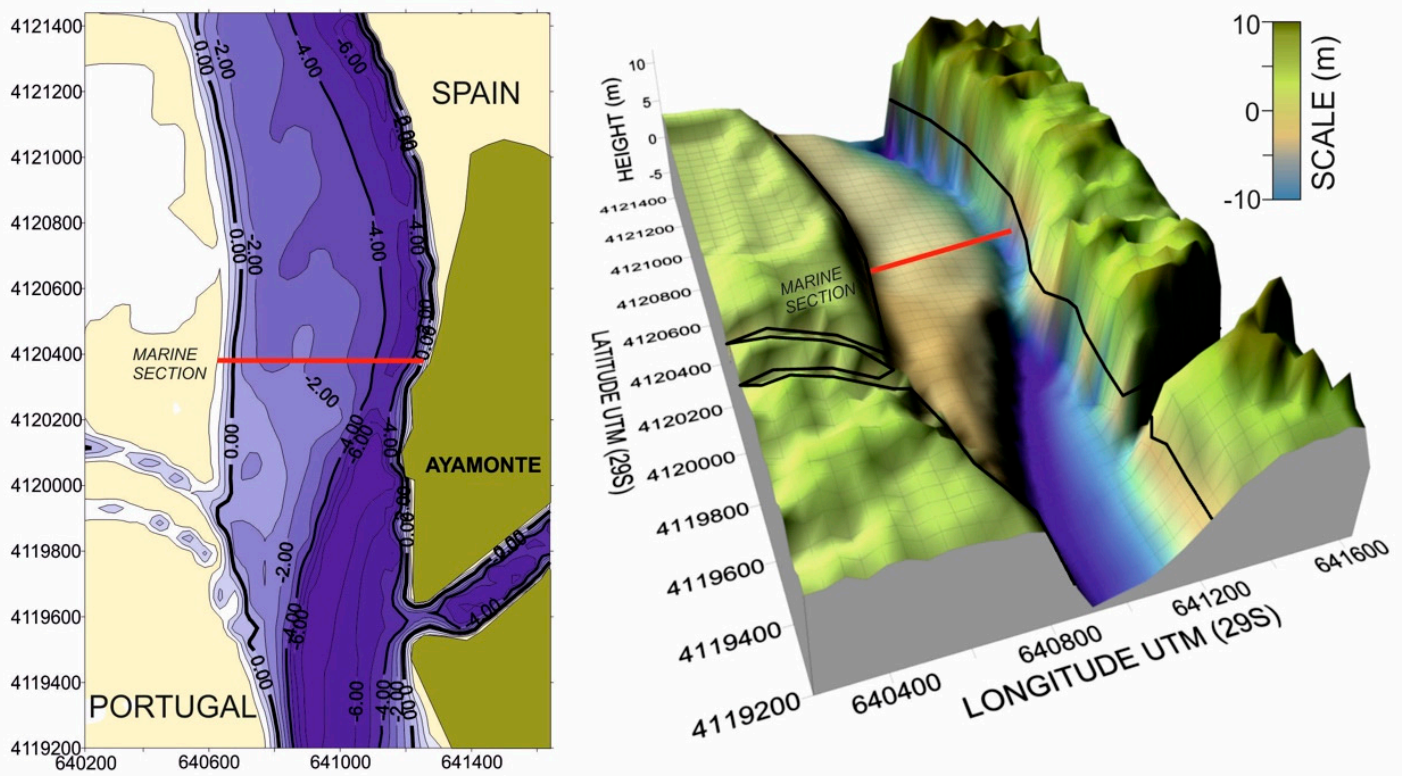

Figure 3. Bathymetric distribution and 3D topographic scheme of the studied areas. Latitude and longitude are expressed in meters, Universal Transverse Mercator coordinates (UTM). (A) Inner estuary area and (B) outer estuary area.

\subsection{Grain Size Distribution}

From a granulometric point of view, five types of beds are distributed within the two studied areas (Figure 4). The inner estuary studied area displays four types: sandy gravels, coarse sands (moderately sorted), muddy sands, and sandy muds, whereas the outer estuary area displays moderately sorted medium sands, well sorted coarse sands, bad sorted muddy sands, and sandy muds. The surficial distribution of each one of these granulometric categories was obtained by comparison of the grain size type with the reflectance pattern of the side-scan sonar records at the geo-referenced point where each sample was taken, in order to elaborate the charts of the sediment types shown in the Figure 5. In addition, erosional rocky outcrops were also identified in the channel margins of the inner area. 


\section{A) INNER ESTUARY AREA}

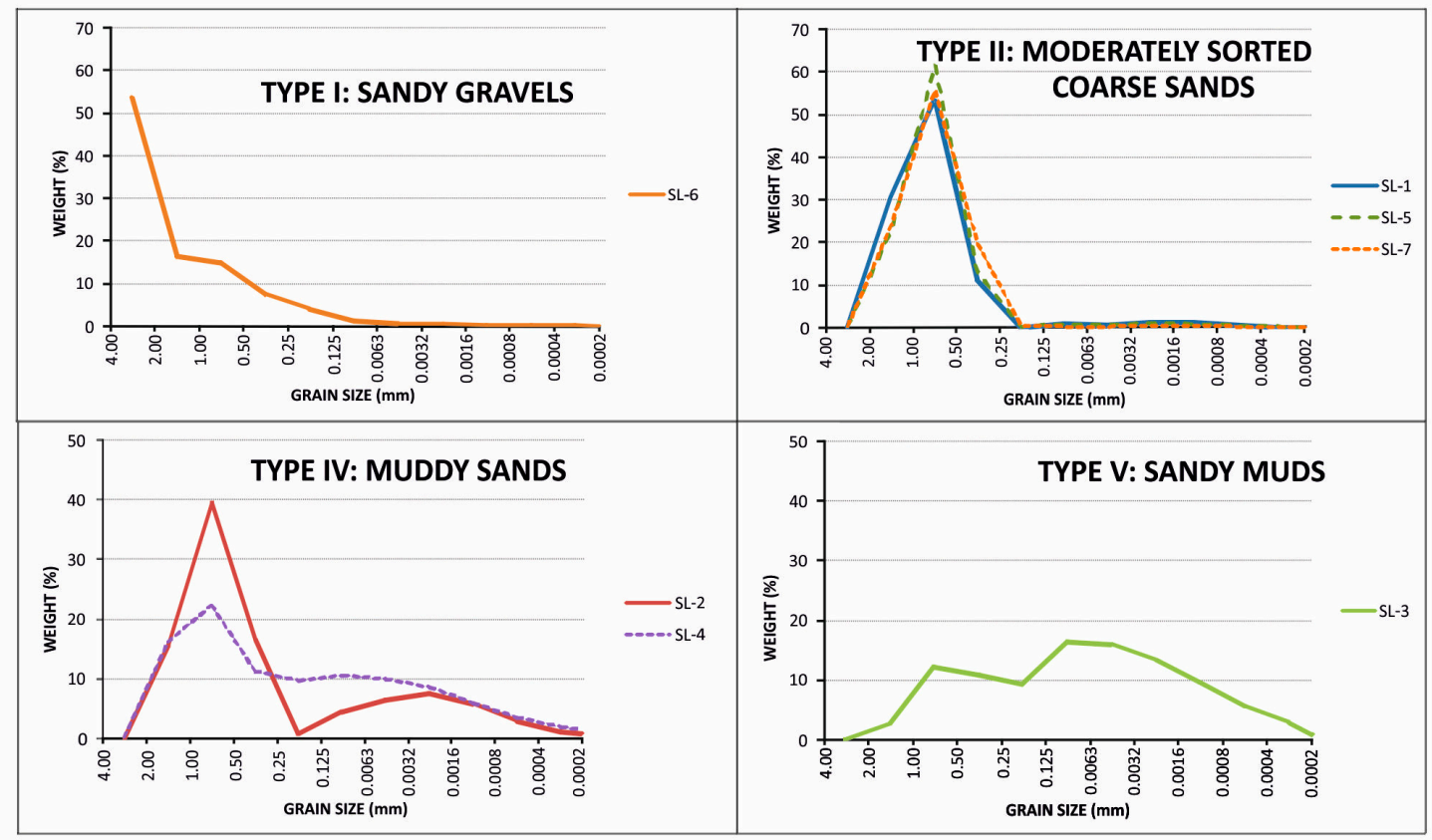

\section{B) OUTER ESTUARY AREA}

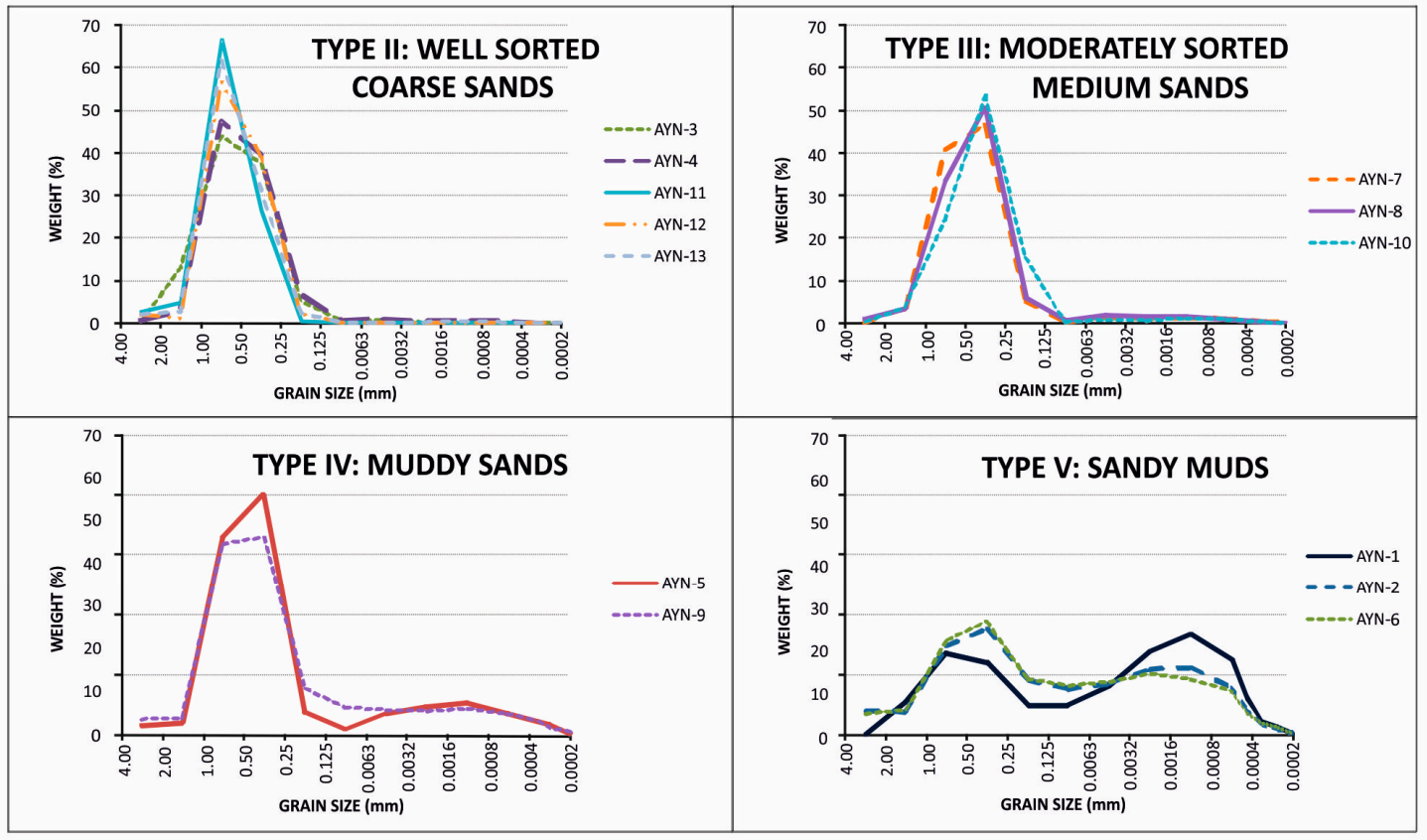

Figure 4. Types of grain size distribution within the (A) inner (fluvial) and (B) outer (marine) studied areas.

The first class of sediment (sandy gravel) is present in the inner area and comprises a high percentage of gravel which can reach up to $50 \%$ of the total sediment (Figure 4). The populations of very coarse and coarse sands are also important, as together they can reach $30 \%$ of the sediment. Medium and fine sands are also present. 


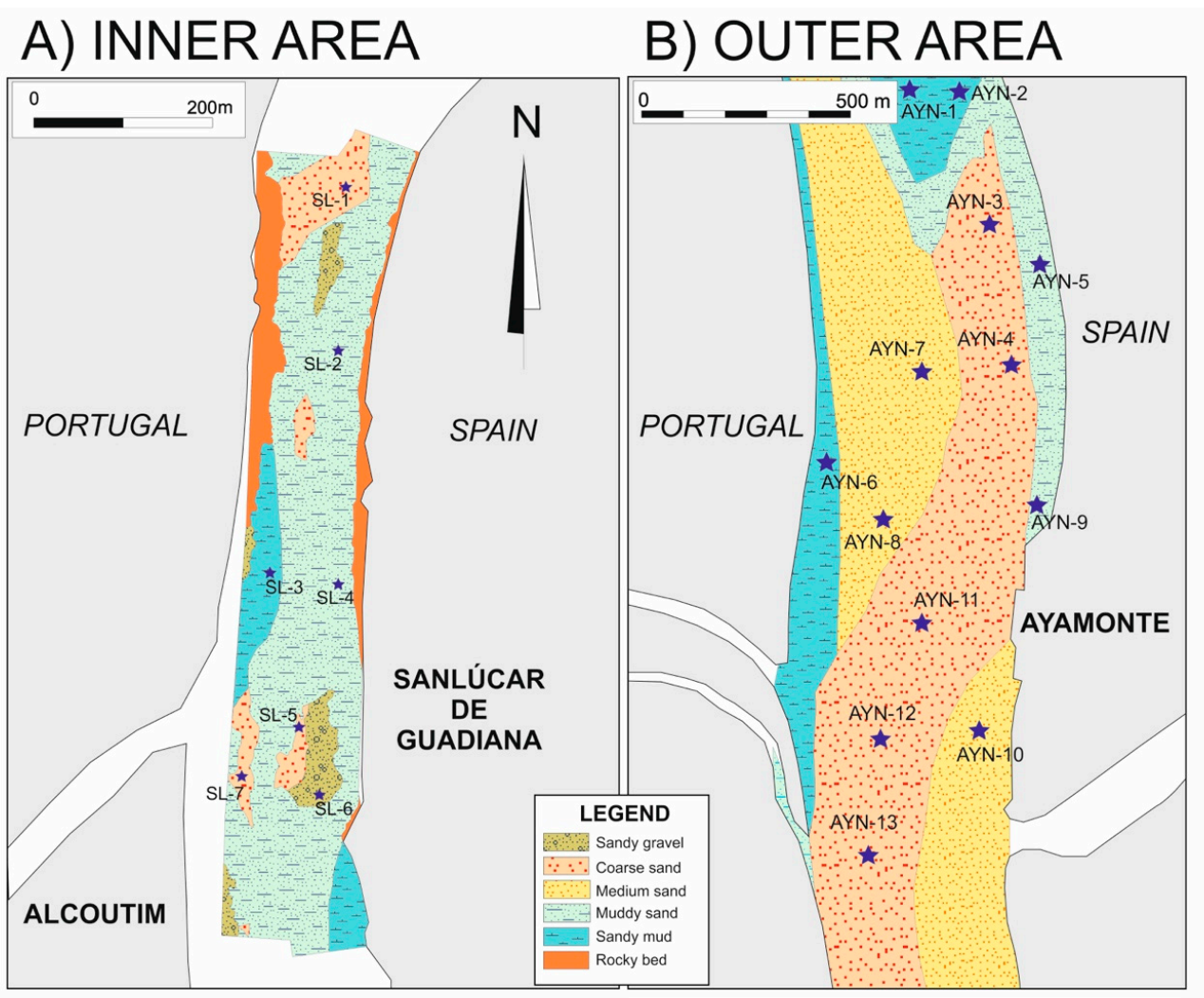

Figure 5. Distribution of the sediment types in the two studied areas. (A) Stars mark the location of the sediment samples. Sampling key: SL = Sanlucar (inner area); (B) AYN = Ayamonte North (outer area).

The second type of sediment is constituted by a dominant coarse sand fraction (Figure 4). In the inner area, this mean size is normally accompanied by a small amount of very coarse and medium sand with a moderate sorting and a symmetric shape. In the main part of the outer area, this coarse sand is well sorted with small populations of medium sand (Figure 4). Nevertheless, in some places of the outer area, the sediment is composed of moderately sorted medium sand with a mesokurtic and positively skewed curve.

The third type of bed consists of medium sand and is only present in the outer area (Figure 4). It is really composed of medium sand with a significant percentage of coarse and fine sand fractions. The grain-size curve also presents moderate sorting, a positive skewness, and a leptokurtic distribution.

The fourth type corresponds to muddy sand and is similar to the third type, except in the presence of silts as a secondary population (Figure 4). In the inner area, these are physically transported silts (coarse and medium silts), while in the outer area, there is a higher amount of fine and very fine silts.

A fifth type of bed is composed of sandy mud (Figure 4). The grain-size curve presents extremely poor sorting with a bimodal distribution, negative skewness, and a platykurtic shape.

The distribution map of the sediment types in the inner fluvial zone (Figure 5a) displays a wide distribution of muddy sands (type IV) in the main part of the channel bed. Not very wide fields of sandy gravels (type I) and coarse sands (type II) are present in the deepest part of the channel. In the shallow marginal bar near Portugal, an elongated lateral bar can be observed; in this case, the bar is mainly composed of sandy muds (type V) but erosional rocky beds can also be observed in these shallow parts of the channel.

The map of sediments within the outer area displays a band of coarse sands (type II) in the deeper part of the channel, whereas the medium sands (type III) are distributed on the lateral bar's surface. In the northern sector of the studied area, the deeper channel is composed of sandy muds (type V). A band of sandy mud is also present in the western border of the lateral bar and another band of muddy sand (type IV) extends along the eastern (Spanish) channel margin. 


\subsection{Bed Type Distribution}

In addition to the extension of the granulometric characteristics, the Side Scan Sonar records (Figures 6 and 7) allow one to observe different bed configurations and morphologies such as erosive and sedimentary features. Dune crests are especially visible and their dimensions and orientation can help with the interpretation of both sedimentary regimes and transport trajectories. Geo-referenced mosaics were elaborated upon to map bedform fields and other bed configurations. To draw these maps information about grain size was also used.

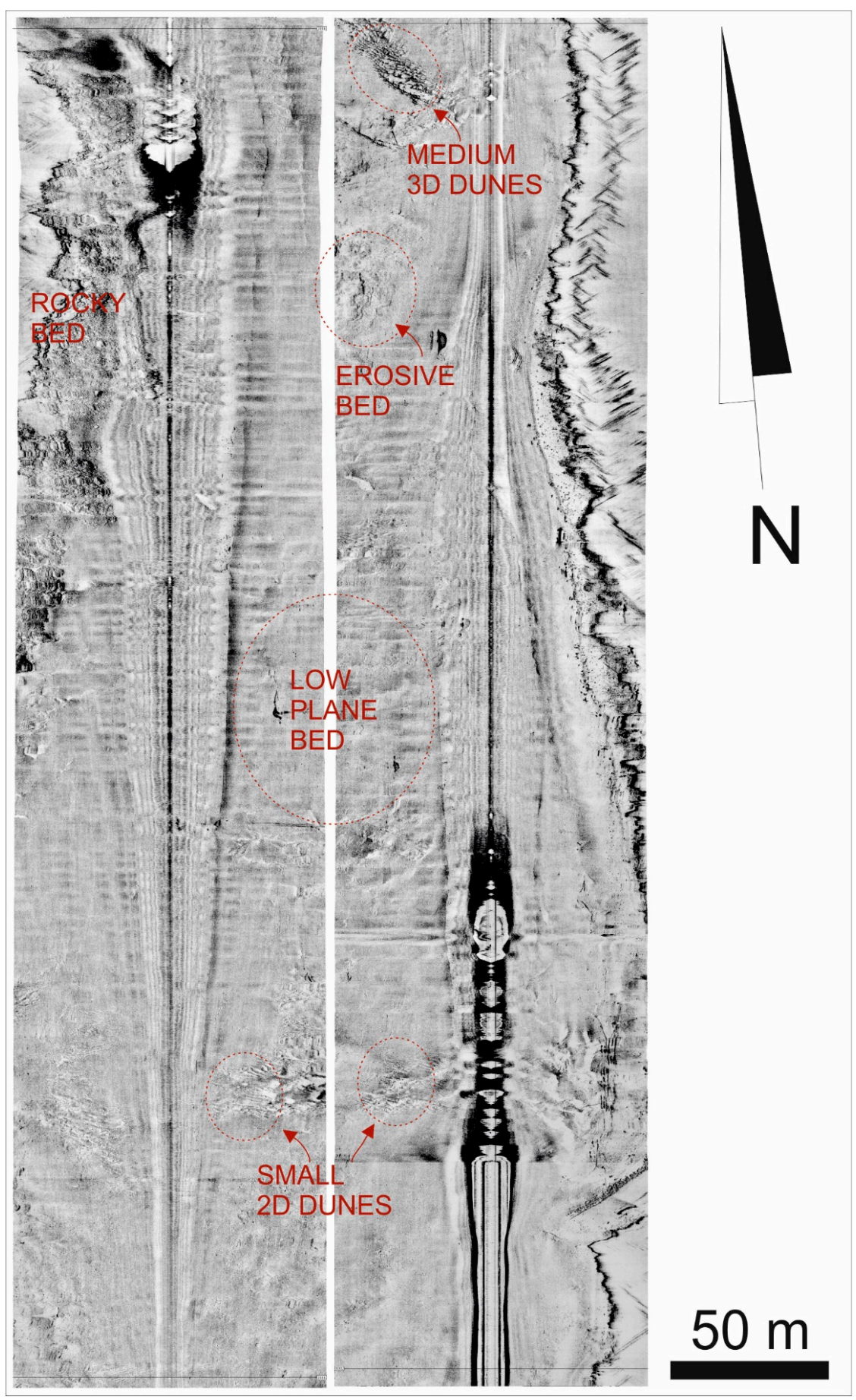

Figure 6. Side-Scan Sonar records covering the inner area. The main distinguished bed features are indicated. 


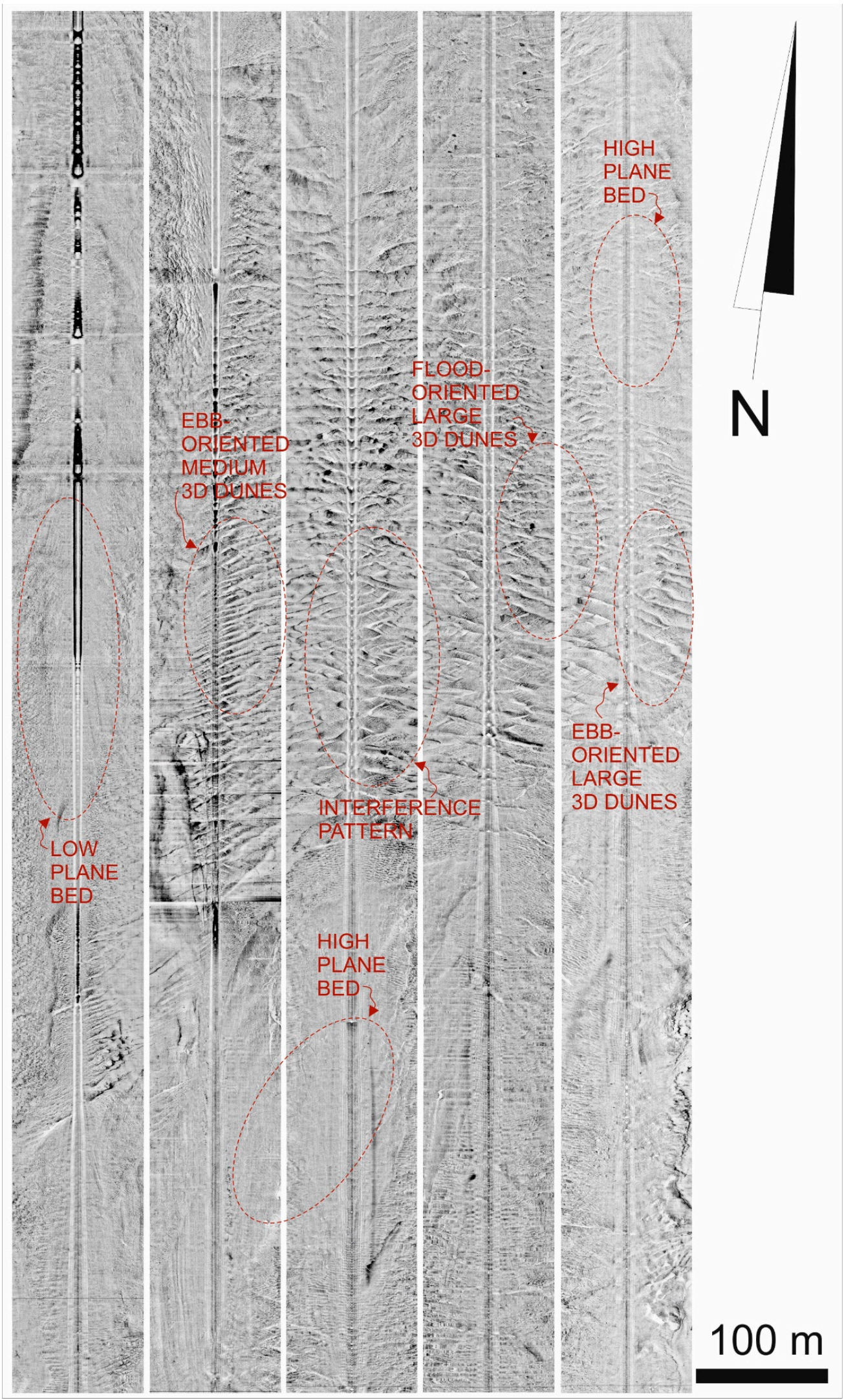

Figure 7. Side-Scan Sonar records covering the outer area. The main distinguished bed features are indicated. 
Taking into account the main lithologies and the distribution of bedform fields, six categories of beds are described in the two studied areas (Figure 8). Four of these beds are depositional (coarse sands with high plane beds, medium sands with medium 3D dunes, medium sands with small 2D dunes and ripple trains, and muddy sands with a low plane bed), whereas there are two types of non-depositional beds (erosive beds and rocky outcrops). A brief description of these bedform fields is provided below.

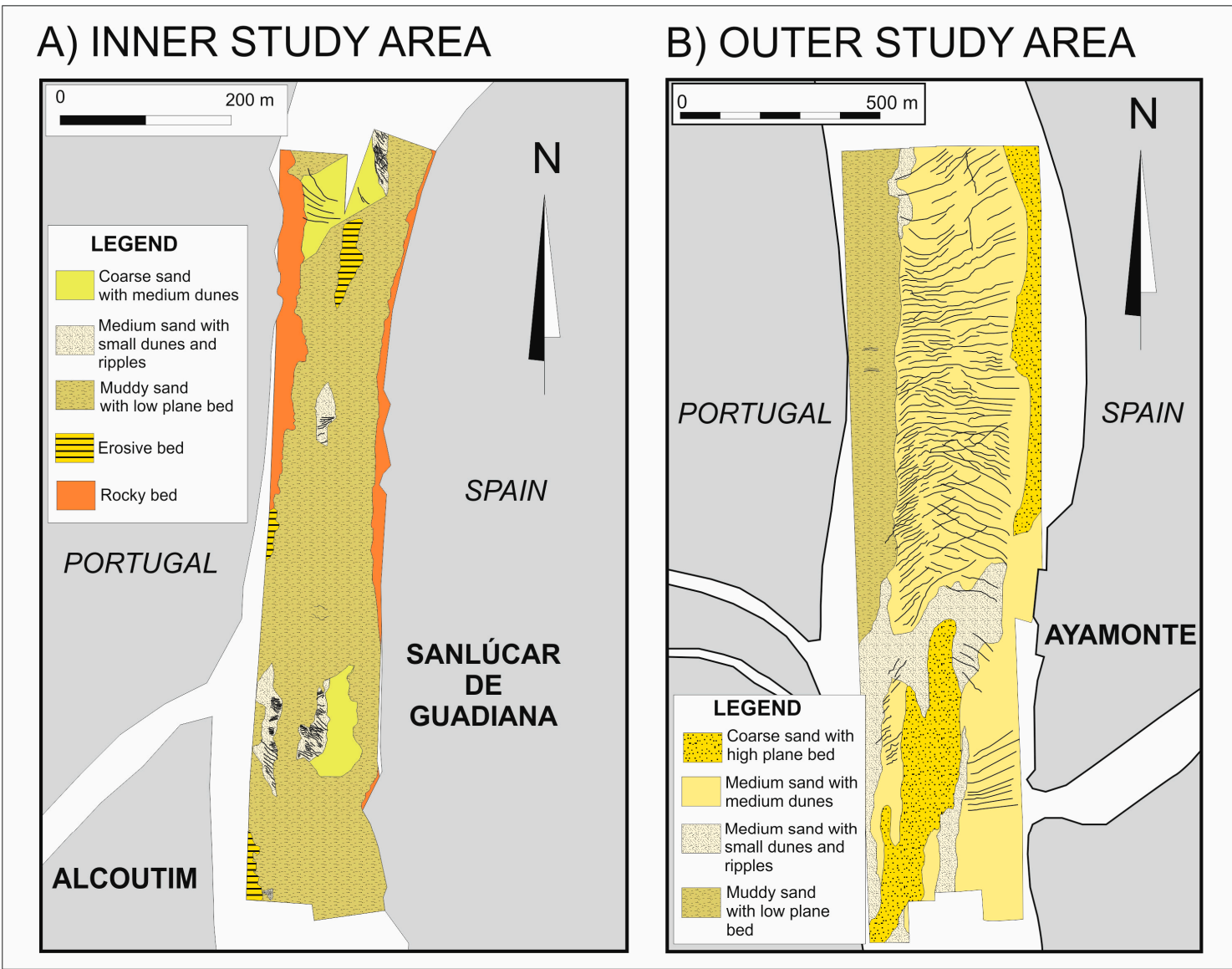

Figure 8. Map of the bed distribution and bedform crests in both studied areas: the (A) inner (fluvial) domain and (B) outer (marine) domain.

Coarse sands with a high plane bed: This type of bed is distributed only in the studied marine zone (Figure 7). It appears in the channel areas at deeper than $4 \mathrm{~m}$ and its lithology is composed of moderately sorted coarse sand with medium sand populations. The absence of large bedforms is significant. The presence of a wide plane bed is interpreted as a product of a high regime flow.

Medium sands with medium 3D dunes: This category of bottom was recognized in both the inner and outer study areas. In the inner estuary area, this bed is composed of coarse sand and is developed in small dimensional patches located in the deep estuarine channel (Figure 6). In this area, the observed ebb-oriented dunes present a regular wavelength of 9-10 m and heights of $0.6 \mathrm{~m}$.

In the outer estuary area, the sediment composing this bed configuration is finer (medium sand) and wide medium 3D dune fields are located on the nearly planar surface of the lateral bar developed in the western margin at 2-4 m deep. The main part of the bar is covered by dunes with straight and sinuous crests. Two trains of dunes are distinguishable (Figure 7): (1) A field of mixed ebband flood-oriented 3D dunes extended at depths between 2 and $3 \mathrm{~m}$. Their dimensions are variable, with the distance between their crests being between 7 and $15 \mathrm{~m}$ and their heights being around $0.50 \mathrm{~m}$. In this bedform field, the crests are disposed $40^{\circ}$ oblique to the bank. (2) A second train extends in the transition, with high plane beds in deeper waters between 3 and $4 \mathrm{~m}$. Greater flood-oriented sinuous 
dunes develop on this surface, with the distances between crests varying between 25 and $50 \mathrm{~m}$ and the dunes having heights around $0.70 \mathrm{~m}$. In this field, the crests are almost perpendicular to the channel axis, and, as a consequence, rotate along the meander. On the central part of the bar, the crests of these two trains become parallel, whereas on the southernmost area of the lateral bar, the two different bedform sets interact, creating an interference oblique plot.

Medium sands with small 2D dunes and ripples: In some of the deeper parts of the channel of the fluvial estuary (the inner studied area), a small extension of elongated patches constituted by medium sand with small 2D dune fields and minor forms appears (Figure 6). These bedforms have a regular wavelength of $3-4 \mathrm{~m}$ and heights of nearly $0.3 \mathrm{~m}$. Their crests are oriented in an oblique orientation to the channel margins, forming an angle of about $30^{\circ}$.

At intermediate depths of the outer estuary area, similar bed fields are observed to separate sand extensions with large 3D dune fields and shallow plane beds of cohesive sediment (Figure 7). However, these dune fields are wider than those observed in the inner area. The dune fields develop as ebb-oriented medium 2D dunes, like minor 3D dunes, and are mainly constituted by medium sand. Wavelengths of almost $5 \mathrm{~m}$ with heights of $0.35 \mathrm{~m}$ are the most common dimensions.

Muddy sands and sandy muds with low plane beds: Beds without visible bedforms formed by cohesive sediments are widely developed in the inner estuary area occupying the main part of the main channel bed (Figure 6), whereas those on the outer studied area extend to the shallowest marginal areas (between 0 and $2 \mathrm{~m}$ ). There, migrating bedforms are absent because the cohesive character of the sediments mainly develops plane beds. Erosional features like lineal furrows can also be present in these lithologies.

Erosive beds: Beds constituted by eroded ancient sediments are especially visible in some sectors of the deep channel in the inner area (Figure 6). Their main observed features are furrows and erosive scarps, which illustrate the sedimentary structures of the eroded formations.

Rocky beds: The channel margins of the inner area (Figure 6) are constituted by hard lithologies that correspond with Paleozoic geologic formations (Shales and Graywackes) which constrain the channel in this sector of the estuary.

\subsection{Hydrodynamic Results and Bedload Transport}

\subsubsection{Ebb and Flood Currents}

As indicated in the Methods section, an ADCP instrument measured the current velocities of the entire water column; however, in this paper, only the values of the near-bottom velocity were used. These values were obtained at the blanking distance, located at $0.5 \mathrm{~m}$ from the bottom. The measurements were recorded in two positions for each studied section during the mean spring and neap tides (Figure 2). The tides were selected according to their coefficients. As is well known, the tidal coefficient is a universal adimensional magnitude which is indicative of the relative position of the Sun and Moon with respect to the Earth, and can be converted with regard to the tidal ranges in each coast all over the world. The coefficient representative of the mean neap tides is around 0.45 and approaches 0.90 for the mean spring tides. The respective curves of the heights and velocities over time were obtained from the deeper data of the total records (Figure 9). For the correct interpretation of these curves, it is necessary to consider that ebb-oriented currents are represented using negative values and floods are represented using positive ones (fluvio-marine studies normally consider these currents to take the sediment out of the system, whereas floods introduce the sediment into the estuary). 


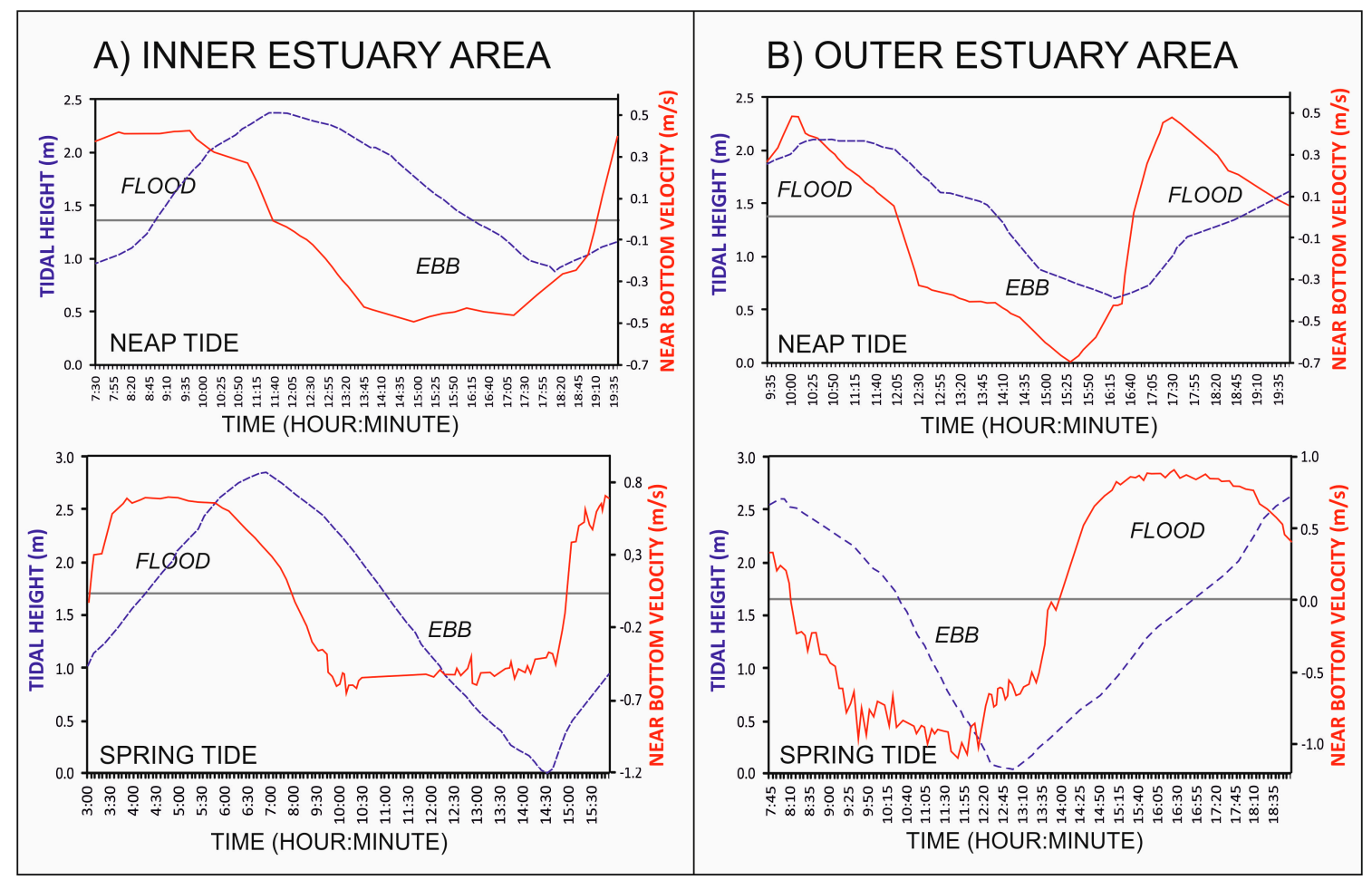

Figure 9. Curves of the water height and near-bottom currents over time in the fluvial estuary (a) and in the marine estuary (b). Measurements during the tidal cycles for the mean neap tide (upper) and mean spring tide (lower). The horizontal grey line refers to the value of 0 for the near-bottom velocity (right vertical axis).

In the fluvial domain (inner estuary area), the neap tide measure was obtained during a tide with a coefficient of 0.46 and a tidal range of $1.50 \mathrm{~m}$, and the spring tide had a coefficient of 0.90 and a tidal range of $2.85 \mathrm{~m}$ (Figure 9a). During the neap tide, the maximum ebb current velocity was $47.7 \mathrm{~cm} / \mathrm{s}$, whereas for the maximum flood it was $42.9 \mathrm{~cm} / \mathrm{s}$. An asymmetry of the acting time is clearly visible in the curves, so the ebb current acted over $6 \mathrm{~h}$ and $35 \mathrm{~min}$, whereas the flood current increased over $5 \mathrm{~h}$ and $54 \mathrm{~min}$. The spring tidal current reached a maximum value of $67.2 \mathrm{~cm} / \mathrm{s}$ during the ebb current, while during the flood, the maximum reached a value of $68.3 \mathrm{~cm} / \mathrm{s}$. In this case, the asymmetry is also visible in the ebb current for $6 \mathrm{~h}$ and $45 \mathrm{~min}$ and is visible in the flood only for $5 \mathrm{~h}$ and $15 \mathrm{~min}$. The presence of reversal currents in the fluvial domain of the estuary, which is completely constituted by sweet water, is a well-known effect of the entrance of marine water into the lower sectors of the estuary and the landwards propagation of the tidal wave. The asymmetry over time and magnitude of the tidal current velocity is also typical of the deformation of the tidal wave when it propagates into the estuary.

In the outer (marine) area, the neap tide measures were recorded with a coefficient of 0.44 and a tidal range of $1.48 \mathrm{~m}$, and the spring tide was measured with a coefficient of 0.91 and a tidal range of $2.58 \mathrm{~m}$ (Figure $9 \mathrm{~b}$ ). The neap tide recorded a maximum measured ebb velocity of $70.7 \mathrm{~cm} / \mathrm{s}$, whereas the flood reached only a maximum value of $54.6 \mathrm{~cm} / \mathrm{s}$. In this case, the asymmetry in the duration of the tidal semicycles was also notable. Thus, the ebb current acted for $6 \mathrm{~h}$ and $20 \mathrm{~min}$ and the flood increased only for $5 \mathrm{~h}$ and $50 \mathrm{~min}$. In the marine area, the spring tide reached the highest values of the current velocity of the entire system. The maximum ebb was $108.4 \mathrm{~cm} / \mathrm{s}$ but the flood reached only $88.7 \mathrm{~cm} / \mathrm{s}$. Like the neap tide, the ebb acted for $5 \mathrm{~h}$ and $57 \mathrm{~min}$ and the flood functioned for only $5 \mathrm{~h}$ and $47 \mathrm{~min}$.

In both areas (and in every measured tide), the asymmetry favored the residual ebb transport because the ebb currents reached higher velocities and acted longer than the flood tides. 


\subsubsection{Potential Bedload Transport Calculation}

The weight of the material potentially transported as the bedload $(Q b)$ was estimated by Bagnold's equation (1963) according to the mathematical process described in the Methods section.

The values of the near-bottom velocity of the previously described velocity curves were used as $U_{(50)}$ (water speed at a distance of $50 \mathrm{~cm}$ from the bed) to obtain the values of $U^{*}$ (the velocity reached on the water-sediment interface). The values of the sediment density and grain size were taken from the sediment samples previously described.

The obtained values of the potential bedload transport are shown in Table 1a. The values of the flow section used to calculate the total potentially transported sediment (in tons) are expressed in Table $1 \mathrm{~b}$; these values were directly measured across the bed in the profiles of Figure 2 . In the inner profile, the total section is $200 \mathrm{~m}$, employing the values of the western current station (measuring point 1) for the 100 shallower meters of the tidal bar and the values of the eastern station (measuring point 2) for the 100 deeper meters of the bypassing channel. In the marine section (outer area), the total flow section is $530 \mathrm{~m}$. The values of the current obtained in the western station (measuring point 3) were used across the $350 \mathrm{~m}$ of the lateral bar and the values of the deeper eastern station (measuring point 4 ) were applied to the $180 \mathrm{~m}$ of the transversal section of the deep channel.

Table 1. Potential bedload transport $(Q b)$ for complete tidal semicycles. (a) Values obtained by application of Bagnold's equation (expressed in $\mathrm{g} / \mathrm{cm}$ ). (b) Values obtained for the complete flow section (expressed in tons).

\begin{tabular}{|c|c|c|c|c|c|c|}
\hline \multicolumn{7}{|c|}{ (A) $Q b(\mathrm{gr} / \mathrm{cm})$} \\
\hline & \multicolumn{3}{|c|}{ INNER STUDY AREA } & \multicolumn{3}{|c|}{ OUTER STUDY AREA } \\
\hline & FLOOD & EBB & BALANCE & FLOOD & EBB & BALANCE \\
\hline NEAP TIDE & 27.75 & -49.84 & -22.09 & 12.11 & -56.44 & -44.33 \\
\hline SPRING TIDE & 121.13 & -129.44 & -8.31 & 209.62 & -233.37 & -23.75 \\
\hline \multicolumn{7}{|c|}{ (B) $Q b$ (tons) } \\
\hline & \multicolumn{3}{|c|}{ INNER STUDY AREA } & \multicolumn{3}{|c|}{ OUTER STUDY AREA } \\
\hline & FLOOD & EBB & BALANCE & FLOOD & EBB & BALANCE \\
\hline NEAP TIDE & 0.56 & -1.00 & -0.44 & 0.64 & -2.99 & -2.35 \\
\hline SPRING TIDE & 2.42 & -2.59 & -0.17 & 11.11 & -12.37 & -1.26 \\
\hline
\end{tabular}

These results show that transport seawards is dominant in both sectors of the estuary (negative values of the balance). All the values of the ebb-transported sediment are higher than the flood ones at all tides and across both stations as a consequence of the aforementioned asymmetry of the action of the tidal currents.

Capacities of the transport of sediment by currents are much higher in the outer estuary, doubling during neap tides and quadrupling for spring tides.

As expected, the potential transport weights are higher during spring tides than during neap tides, in both tidal senses. However, taking into account the net balances, the weight of the seawards-transported sediment is higher during the neap tides, reaching values two times higher in the outer estuary and values nearly four times higher in the inner estuary.

\subsection{Real Bedload Transport}

While ADCP was recording the tidal current speeds, Poliakoff sediment traps [19] were installed at the same measuring points to obtain contemporary values for the real transport. These values for the real transported bedloads are expressed as $S b$ (in $\mathrm{g} / \mathrm{cm}$ ) in Table 2a. To calculate the total transport in tons (Table 2b), the same flow sections used in the calculation of the total potential transport were employed. 
Table 2. Material caught by traps and considered real bedload transport $(S b)$ for the complete tidal semicycles. (a) Values expressed in $\mathrm{g} / \mathrm{cm}$ obtained directly from traps (sediment weight divided between the $30 \mathrm{~cm}$ of the trap section). (b) Values obtained for the complete flow section (expressed in tons).

\begin{tabular}{|c|c|c|c|c|c|c|}
\hline \multicolumn{7}{|c|}{ (A) $S b(\mathrm{gr} / \mathrm{cm})$} \\
\hline & \multicolumn{3}{|c|}{ INNER STUDY AREA } & \multicolumn{3}{|c|}{ OUTER STUDY AREA } \\
\hline & FLOOD & EBB & BALANCE & FLOOD & EBB & BALANCE \\
\hline NEAP TIDE & 13.23 & -30.17 & -16.94 & 5.90 & -14.60 & -8.70 \\
\hline SPRING TIDE & 109.91 & -114.87 & -4.95 & 69.41 & -72.10 & -2.69 \\
\hline \multicolumn{7}{|c|}{ (B) $S b$ (tons) } \\
\hline & \multicolumn{3}{|c|}{ INNER STUDY AREA } & \multicolumn{3}{|c|}{ OUTER STUDY AREA } \\
\hline & FLOOD & EBB & BALANCE & FLOOD & EBB & BALANCE \\
\hline NEAP TIDE & 0.26 & -0.60 & -0.34 & 0.31 & -0.77 & -0.46 \\
\hline SPRING TIDE & 2.20 & -2.30 & -0.10 & 3.68 & -3.82 & -0.14 \\
\hline
\end{tabular}

Along with the potential transport case, it can be observed that all values of $S b$ during the ebb conditions outweigh the flood values at all tides and in both stations, always resulting in a net balance of transport seawards. The net balance of sediment transported during spring tides is nearly triple that obtained during the neap tides in both studied sections.

Contrary to what is observed for the potential transport, the rate of sediment transported across the inner estuary is nearly double that of the value obtained for the outer estuary. Nevertheless, when calculating the total weight of the transported material across the entire section, the values of the outer estuary are higher because they pass across a longer section. In this case, significant differences between the inner and outer estuary are not observed in any tidal range.

A comparison between potential and real transport can be done via the percentage of potential transport covered by real transport (Table 3). Normally, we consider real transport to be controlled by the availability of sediments.

Table 3. Percentage of $Q b$ covered by $S b$ (availability of sediments) for complete tidal current cycles.

\begin{tabular}{ccccc}
\hline & \multicolumn{2}{c}{ INNER STUDY AREA } & \multicolumn{2}{c}{ OUTER STUDY AREA } \\
\hline & FLOOD & EBB & FLOOD & EBB \\
\hline NEAP TIDE & $47.68 \%$ & $60.53 \%$ & $48.69 \%$ & $25.86 \%$ \\
SPRING TIDE & $90.74 \%$ & $88.74 \%$ & $33.11 \%$ & $30.89 \%$ \\
\hline
\end{tabular}

In the fluvial estuary, the values of potential transport exceed $88 \%$ of those of real transport during spring tides; however, these values only approach $50 \%$ during neap tides. In the marine estuary, real transport is even lower (around 30\%), except in the case of neap tidal floods, where real transport reaches $48 \%$.

\section{Discussion}

Two estuarine channel sectors have been studied in this paper from a sedimentary-dynamic point of view. The inner area is a section of the fluvial estuary and consists of an asymmetric channel with erosional rocky or highly cohesive margins and a high-slope lateral bar constituted by sandy sediments. The outer area comprises a flat lateral tidal bar extending in the shallower zones and a bypassing channel in the deeper area, following the criteria suggested by Morales et al. (2006) [33].

Regarding the facies and bedform field distribution, the flow regime decreases from shallow to deep areas in both estuarine sections. In the inner area, the main part of the bed is formed by muddy sands and sandy muds with a cohesive character, which problematizes bedload transport. Only in the deeper part of the channel does the bed show bedform fields formed by non-cohesive lithologies 
as evidence of more active bypassing in these areas. In the outer area, a low plane bed extends by the banks and evolves into a lateral tidal bar where medium and small dunes with superimposed minor forms are developed. In the same transection, the deep channel works as a bypassing channel displaying a coarse-sand plane bed that indicates a high flow regime. An increase in the flow regime (from low in the shallower areas to high in the deep channel) is clearly visible.

The most interesting areas are the surfaces of the outer lateral tidal bar, which display a near horizontal upper surface that is completely covered by dunes with different orientations. This dispersion of bedform senses has been previously observed by Lobo et al. (2004) [10] using a mono-beam echo sound, but the cause of the coexistence of both ebb and flood bedforms in the same bedform fields remains unexplained. The same Side Scan Sonar records used in this work have been analyzed by us in a previous paper [36]. These records allowed us to construct a map of dominant flow vectors (Figure 10). Like in the ebb medium, the 3D dunes visible in this map follow a N-S dominant migration that longitudinally crosses the lateral bar. By contrast, the observable flood dunes are oriented in secondary trajectories surrounding the following rotation in the orientation of the dune crests, merging the dominant flood trajectories parallel to the deep bypassing channel. Minor flood forms are also observed in the southern border. In this case, the small forms climb the slope of the bar as a flood ramp. This may occur because the deeper channel acts as a reverse bypassing channel during the entire tidal cycle, but the exclusive presence of large ebb bedforms is clear evidence of the dominant ebb balance observed in the values of the net sediment transport.

Values for the potential bedload transport have been estimated using the near bottom current velocities and grain size parameters in two sections of the estuary during both neap and spring tidal conditions. In a general way, it can be affirmed that the capacities of the sediment transport of the ebb currents are higher than the flood ones under every tidal condition. Thus, the net transport balance occurs during the ebb. The values of the net potential transport balance are much higher in the outer estuary than in the inner estuary, reaching over double during the neap tides and triple for the spring tides. The tidal asymmetry in the potential transport is, in relative terms, higher during the neap tidal conditions and, in this case, is higher in the inner estuary.

The real bedload transport values were also obtained using Poliakoff type sediment traps at the same time the near-bottom currents were being measured. The total weight of the sand transported as bedload also showed a net balance for the ebb and also presented relatively higher values during the neap tides than during the spring tides.

The values for the real $S b$ are substantially lower than the calculated $Q b$ in every condition. The fluvial estuary values of real sand tidal transport during spring tides represent nearly $90 \%$ of the potential transport. However, during neap tides, this value is only near $50 \%$. This fact may be due to the influence of cohesive materials present in the matrix of the sediment, which inhibits the bypassing of coarser particles during smaller flows. This makes the sandy sediments flow only during more energetic tidal conditions or fluvial floods. In the marine estuary (outer section), the rate between the real $(S b)$ and potential $(Q b)$ transport is even lower (approaching 30 per cent). In this case, the absence of cohesive sediment facilitates the movement of the particles. The rate of $S b / Q b$ approaches $4 / 5$ in the inner estuary and about $1 / 3$ in the outer estuary. A high capacity for transport but a low sediment availability can be deduced from these data. These values strongly contrast with those obtained in the Piedras river mouth using the same sediment traps and the same installation [39] where the values for the real transport were nearly $100 \%$ of the calculated potential bedload in a well-fed area. The net amount of the sediment transported across the inner transection of the estuary reached 0.34 tons per tidal neap cycle and 0.10 tons during the spring tidal cycle, while in the outer areas, the values of the transported material were higher, reaching 0.46 tons in neap tidal conditions and 0.14 tons during spring tide. This fact induces deficit conditions in the sedimentary supply and forces a reworking of the sediments previously deposited in the intermediate estuarine sectors. This process is related to the presence of frequent erosive areas in the inner estuary, as observed in the Side Scan Sonar records. 


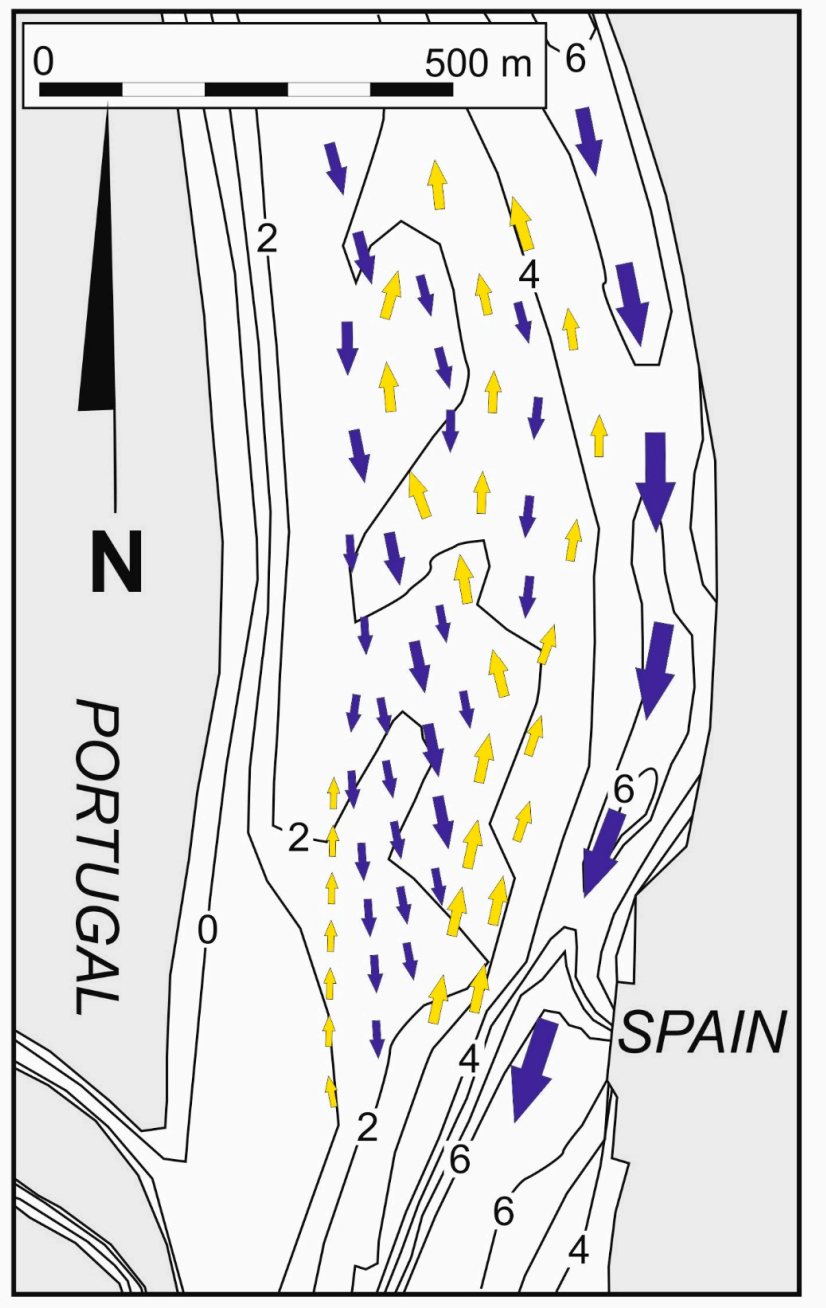

Figure 10. Main patterns of sand transportation in the outer area according to the sense of the dune's crests. Yellow (clear) arrows indicate the trajectories of the flood transport and blue (dark) arrows indicate the trajectories of the ebb transport. The size of the arrows is indicative of the intensity of the transport according to the dune size.

The annual balance of sediments offers a value of $258.56 \mathrm{~m}^{3}$ for the sand that is actually transported seawards across the section of the inner estuary and $352.59 \mathrm{~m}^{3}$ across the marine section. These obtained volumes are lower than those estimated by Garel and Ferreira (2011) [30], who calculated the annual balanced potential bedload across a close marine estuary section, resulting in $5400 \mathrm{~m}^{3}$ per year in conditions with low fluvial discharge, and are even smaller compared to the values obtained by Portela (2006) [40], who calculated an average sand supply of $10^{5} \mathrm{~m}^{3}$ per year for a period of 20 years between 1980 and 2000. This can be interpreted as more evidence for a poorly fed system.

Previous papers $[27,29,30,40]$ have attributed the cause of this deficit to the recent building of an enormous dam in Alqueva, which is located at the last point of tidal influence into the estuary. Indeed, our preliminary paper [36], which analyzed only the data from the marine domain, suggested this result. The presence of this barrier inhibits the bypass of sands transported from the river basin, thereby necessarily diminishing the sediment availability of the estuary. Thus, the sand presently transported to the sea across the estuary is the sand located downstream from the dam at the moment of its building.

It is also possible that the relationships between the potential and real transports and this deficit are a typical condition of the estuary and have remained since before the construction of the dam. 
It is, therefore, necessary to note that our data from the inner section show that under normal fluvial discharge conditions, the sand supply that enters the estuary across the fluvial domain is greatly inferior to the capability of transport sands in the lower domains, even if $S b$ completes $100 \%$ of $Q b$ (as during conditions prior to the dam). With these budgets for sediment inputs, a deficit of sand in the lower tracks of the estuary could be an intrinsic behavior of the system.

Nevertheless, the ebb current observed in our experiment occurred in conditions of regulated fluvial discharge. During conditions with a higher fluvial caudal, a stronger asymmetry of the tidal currents is expected, with stronger ebb currents and lower flood ones. Under these conditions, the values of the net potential transport would be higher. In addition, the absence of the dam available to these currents introduces significant amounts of sand to generate a budget in the central estuary and increments the sediment availability in the marine sector to supplement its empty potential bedload. These conditions have mentioned by authors like Portela [24] in records prior to the building of the Alqueva dam, but such conditions are now impossible because of the dam's presence.

\section{Conclusions}

In natural systems, the use of equations and models to calculate bedload transport are normalized. Nonetheless, very few papers have calibrated the calculated potential transport with direct measures of the bedload. This paper has demonstrated the utility of this kind of comparison, since, in some conditions (as in the case of strongly regulated systems), a disparity exists between potential and real transport. In these cases, the use of only potential transport data would provide a misconception of the system's dynamics.

In this study case of the Guadiana estuary, the values of real transport were found to be smaller than the estimated bedload under every tidal condition. In the fluvial domain, the potential and real values were closer, but even in this situation, the sand input that entered the lower sectors of the estuary was found to be not enough to feed the potential capacity of the tidal currents to move the bedload sediment in these domains. Consequently, a deficit of sand was observed in these sectors in which the real bedload was only near $1 / 3$ of the potential transport.

The presence of one of the biggest dams in Europe at the last point of tidal influence in this estuary manifests in the fluvial domain of the estuary, not only causing a deficit of the available sediment but also producing a decrease in the potential transport. After the building of the dam, the bypassing of the sand to the sea continues, as demonstrated by the presence of a lateral tidal bar covered by dominant ebb-oriented dunes in the marine estuary. Nevertheless, the sand transported across these sections is only the sand that was already downstream of the dam at the time of its construction. The cohesive mud resulting from the flocculation processes induced by tides could help to retain part of these sands in the estuary.

Author Contributions: The first author, J.A.M. was the administrator and supervisor of the project, so as the planner of the survey from a methodological point of view. He also contributed to the statistical analysis of the sedimentological data and was the main writer of the original manuscript. M.S. was the manager during the acquisition and processing of the current velocity data. He also reviewed and edited the first draft. Finally, C.L. managed all concerning of the sediment traps, since their installation on the bed to the processing of final results. He also elaborated the ortophotomosaic of the Side Scan Sonar Images.

Funding: This investigation was carried out with a grant from the Andalousian Gouvernement (Andalousian Plan I+D+i). Excelence Project RNM-03093.

Acknowledgments: We strongly acknowledge the help of M. González, J. Rangel, and J. Galvez during the development of the field work. The help of M. Cantano, I. Delgado, G. Flor-Blanco, and A. Rodríguez-Ramirez was also essential during the development of this project and processing of the preliminary results. These individuals also participated in the redaction of a preliminary paper of this experiment. The Poliakoff sediment traps could not be built without the kind contribution of J. Guillén from the CSIC, Institute of Sea Sciences (Barcelone). We acknowledge the comments of the anonymous reviewers who have contributed to improving the final version of the manuscript. 
Conflicts of Interest: The authors declare no conflict of interest. The funders had no role in the design of the study; in the collection, analyses, or interpretation of data; so as in the writing of the manuscript, or in the decision to publish the results.

\section{References}

1. Dalrymple, R.W.; Knight, R.J.; Lambiase, J.J. Bedforms and their hydraulic stability relationships in a tidal environment, Bay of Fundy. Canada. Nature 1978, 275, 100-104. [CrossRef]

2. Berg, J.H.; Berg, J.V.D. Bedform migration and bed-load transport in some rivers and tidal environments. Sedimentology 1987, 34, 681-698. [CrossRef]

3. Fry, V.A.; Aubrey, D.G. Tidal velocity asymmetries and bedload transport in shallow embayments. Estuar. Coast. Shelf Sci. 1990, 30, 453-473. [CrossRef]

4. Gomez, B. Bedload transport. Earth-Sci. Rev. 1991, 31, 89-132. [CrossRef]

5. Masselink, G.; Cointre, L.; Williams, J.; Gehrels, R.; Blake, W. Tide-driven dune migration and sediment transport on an intertidal shoal in a shallow estuary in Devon, UK. Mar. Geol. 2009, 262, 82-95. [CrossRef]

6. Gomez, E.A.; Cuadrado, D.G.; Pierini, J.O. Sand transport on an estuarine submarine dune field. Geomorphology 2010, 121, 257-265. [CrossRef]

7. Fenster, M.S.; Fitzgerald, D.M.; Kelley, J.T.; Belknap, D.F.; Buynevich, I.V.; Dickson, S.M. Net ebb sediment transport in a rock-bound, mesotidal estuary during spring-freshet conditions: Kennebec River estuary, Maine. GSA Bull. 2001, 113, 1522-1531. [CrossRef]

8. Wu, J.; Wang, Y.; Cheng, H. Bedforms and bed material transport pathways in the Changjiang (Yangtze) Estuary. Geomorphology 2009, 104, 175-184. [CrossRef]

9. Meade, R.H. Wave-like movement of bedload sediment, East Fork River, Wyoming. Environ. Geol. Water Sci. 1985, 7, 215-225. [CrossRef]

10. Fenster, M.; Fitzgerald, D. Morphodynamics, stratigraphy, and sediment transport patterns of the Kennebec River estuary, Maine, USA. Sediment. Geol. 1996, 107, 99-120. [CrossRef]

11. Fitzgerald, D.; Buynevich, I.; Fenster, M.; McKinlay, P. Sand dynamics at the mouth of a rock-bound, tide-dominated estuary. Sediment. Geol. 2000, 131, 25-49. [CrossRef]

12. Yang, C.-S. On Bagnold's sediment transport equation in tidal marine environments and the practical definition of bedload. Sedimentology 1986, 33, 465-486. [CrossRef]

13. Rubin, D.M.; Ikeda, H. Flume experiments on the alignment of transverse, oblique, and longitudinal dunes in directionally varying flows. Sedimentology 1990, 37, 673-684. [CrossRef]

14. Gomez, B.; Hubbell, D.W.; Stevens, H.H. At-a-point bedload sampling in the presence of dunes. Water Resour. Res. 1990, 26, 2717-2731. [CrossRef]

15. Bagnold, R.A. Mechanics of marine sedimentation. The Sea: Ideas and Observations. Interscience 1963, 3 , 507-528.

16. Einstein, H.A. Formulae for the transportation of bed load. Trans. Am. Soc. Civ. Eng. 1942, 107, 561-577.

17. Van Rijn, L.C. Computation of Bed-Load Concentration and Bed-Load Transport; Delft Hydraulics Laboratory Research Report S487-L; Delft Hydraulics Laboratory: Delft, The Netherlands, 1981; p. 43.

18. Yalin, M.S. An expression for bed-load transportation. J. Hydraul. Div. 1963, 89, 221-250.

19. Hu, X.; Yang, F.; Song, L.; Wang, H. An Unstructured-Grid Based Morphodynamic Model for Sandbar Simulation in the Modaomen Estuary, China. Water 2018, 10, 611. [CrossRef]

20. Petti, M.; Bosa, S.; Pascolo, S. Lagoon Sediment Dynamics: A Coupled Model to Study a Medium-Term Silting of Tidal Channels. Water 2018, 10, 569. [CrossRef]

21. Li, Y.; Song, Z.; Peng, G.; Fang, X.; Li, R.; Chen, P.; Hong, H. Modeling Hydro-Dynamics in a Harbor Area in the Daishan Island, China. Water 2019, 11, 192. [CrossRef]

22. He, Z.; Hu, P.; Zhao, L.; Wu, G.; Pähtz, T. Modeling of Breaching Due to Overtopping Flow and Waves Based on Coupled Flow and Sediment Transport. Water 2015, 7, 4283-4304. [CrossRef]

23. Palanques, A.; Guillén, J.; Camp, J. The effects of damming on sediment and water discharge of the Ebro River into the Mediterranean Sea. In Proceedings of the XXXII nd Congress and Plenary Assembly of ICSEM, Perpignan, France, 15-20 October 1990; p. 86.

24. Guillén, J.; Díaz, J.I.; Palanques, A. Cuantificación y evolución durante el siglo XX de los aportes de sedimento transportado en carga de fondo por el Río Ebro al medio marino. Rev. Soc. Geol. España 1991, 5, $27-37$. 
25. Guillén, J.; Palanques, A. Sediment dynamics and hydrodynamics in the lower course of a river highly regulated by dams: the Ebro River. Sedimentology 1992, 39, 567-579. [CrossRef]

26. Silva, A.J.; Lino, S.; Santos, A.I.; Oliveira, A. Near bottom sediment dynamics in the Guadiana Estuary. Thalassas 2003, 9, 180-182.

27. Lobo, F.J.; Plaza, F.; González, R.; Dias, J.M.A.; Kapsimalis, V.; Mendes, I.; Díaz del Río, V. Estimations of bedload sediment transport in the guadiana Estuary (SW Iberian Peninsula) during low river discharge periods. J. Coast. Res. 2004, 41, 12-26.

28. Morales, J.A. Evolution and facies architecture of the mesotidal Guadiana River delta (S.W. Spain-Portugal). Mar. Geol. 1997, 138, 127-148.

29. Garel, E.; Pinto, L.; Santos, A.; Ferreira, O. Tidal and river discharge forcing upon water and sediment circulation at a rock-bound estuary (Guadiana estuary, Portugal). Estuar. Coast. Shelf Sci. 2009, 84, 269-281. [CrossRef]

30. Garel, E.; Ferreira, O. Effects of the Alqueva Dam on Sediment Fluxes at the Mouth of the Guadiana Estuary. J. Coast. Res. Spec. Issue 2011, 64, 1505-1509.

31. Heathershaw, A. Comparisons of Measured and Predicted Sediment Transport Rates in Tidal Currents. Dev. Sedimentol. 1981, 32, 75-104.

32. Williams, J.J.; Thorne, P.D.; Heathershaw, A.D. Comparisons between acoustic measurements and predictions of the bedload transport of marine gravels. Sedimentology 1989, 36, 973-979. [CrossRef]

33. Morales, J.; Delgado, I.; Gutiérrez-Mas, J. Sedimentary characterization of bed types along the Guadiana estuary (SW Europe) before the construction of the Alqueva dam. Estuar. Coast. Shelf Sci. 2006, 70, 117-131. [CrossRef]

34. Morales, J.A. Sedimentologia del Estuario del Rio Guadiana (S.W. España-Portugal). Ph.D. Thesis, University of Sevilla, Seville, Spain, 1993; p. 274.

35. Morales, J.A.; Pendon, J.G.; Borrego, J. Origen y evolución de flechas litorales recientes en la desembocadura del estuario mesomareal del rio Guadiana (Huelva, SW España). Rev. Soc. Geol. España 1994, 7, 155-167.

36. Morales, J.A.; Sedrati, M.; Cantano, M.; Rodríguez-Ramírez, A.; Delgado, I.; Lozano, C.; Flor-Blanco, G. From the continent to the coast: The bedload transport across the lower sector of the Guadiana River Mouth (Spain-Portugal). Géomorphol. Relief Process. Environ. 2014, 3, 251-260. [CrossRef]

37. Wang, Y.P.; Gao, S. Modification to the Hardisty Equation, Regarding the Relationship Between Sediment Transport Rate and Particle Size. J. Sediment. Res. 2001, 71, 118-121. [CrossRef]

38. Shingal, H.S.S.; Joshi, G.C.; Verma, R.S. Sediment sampling in rivers and canals. Erosion and Sediment Transport Measurement. IAHS Spec. Publ. 1981, 133, 169-175.

39. Morales, J.A.; Delgado, I.; Lozano, C.; Medina, J.M.; Palmeiro, A.; Martín, M. Estimaciones y medidas de transporte de arenas como carga de fondo en la desembocadura del estuario del Piedras (Huelva, SO España). Geo-Temas 2013, 14, 159-162.

40. Portela, L. Sediment delivery from the Guadiana estuary to the coastal ocean. J. Coast. Res. Spec. Issue 2006, $39,1819-1823$.

(C) 2019 by the authors. Licensee MDPI, Basel, Switzerland. This article is an open access article distributed under the terms and conditions of the Creative Commons Attribution (CC BY) license (http://creativecommons.org/licenses/by/4.0/). 